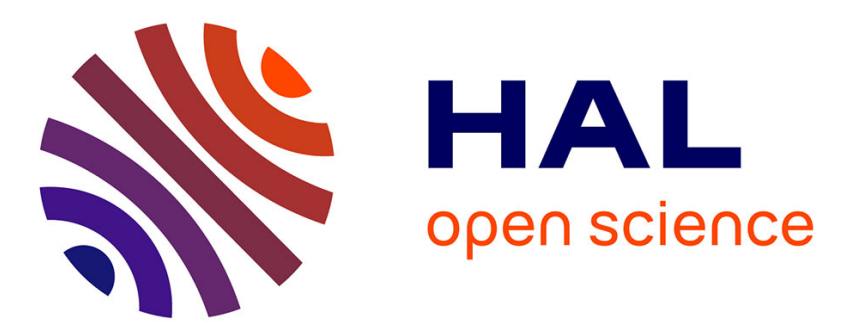

\title{
Cadmium telluride detector development and use in reentry vehicle applications
}

\author{
R.B. Lyons
}

\section{To cite this version:}

R.B. Lyons. Cadmium telluride detector development and use in reentry vehicle applications. Revue de Physique Appliquée, 1977, 12 (2), pp.385-389. 10.1051/rphysap:01977001202038500 . jpa-00244179

\section{HAL Id: jpa-00244179 https://hal.science/jpa-00244179}

Submitted on 1 Jan 1977

HAL is a multi-disciplinary open access archive for the deposit and dissemination of scientific research documents, whether they are published or not. The documents may come from teaching and research institutions in France or abroad, or from public or private research centers.
L'archive ouverte pluridisciplinaire HAL, est destinée au dépôt et à la diffusion de documents scientifiques de niveau recherche, publiés ou non, émanant des établissements d'enseignement et de recherche français ou étrangers, des laboratoires publics ou privés. 


\title{
CADMIUM TELLURIDE DETECTOR DEVELOPMENT AND USE IN REENTRY VEHICLE APPLICATIONS
}

\author{
R. B. LYONS \\ Aeronutronic Division Aeronutronic Ford Corporation Newport Beach, California 42663, U. S. A.
}

\begin{abstract}
Résumé. - On décrit un ensemble électronique-détecteur permettant l'emploi de compteurs CdTe compensé au chlore au moment de la rentrée de fusées dáns l'atmosphère. Les problèmes de microphonie et de résistance du détecteur aux chocs violents ont fait l'objet de recherches approfondies.
\end{abstract}

Abstract. - The development of an electronics packaging design which enables the use of chlorine doped CdTe detectors in the high dynamic environments associated with reentry in atmosphere is described. Special attention is devoted to the elimination of microphonics and to the shock absorbant around the detector.

1. Introduction. - In 1973 Aeronutronic Ford undertook the development of a miniature gamma ray detector package capable of warm operation as a calibrated event counter in a severe vibration/acoustic environment.

The environment consists of a combination of linear accelerations in the order of $100 \mathrm{~g}$ 's, vibration in the order of $60 \mathrm{~g}$ 's RMS, and acoustic power spectral densities in the order of $120 \mathrm{~dB} / \mathrm{Hz}$ extending out to several hundred kilo Hertz. Operating temperatures were expected to range from 50 to $100 \mathrm{D}$, moderate electro-magnetic interference was expected from UHF transmitters and other electrical equipment associated with the device application.

Chlorine doped cadmium telluride was selected as the actual gamma detector material and the detector was packaged along with all associated analog electronics and some acoustic isolation in a single hybrid package. Cadmium Telluride detector material was selected because of its (relatively) high gamma detection efficiency and room temperature operation capability.

The hybrid package combination of detector, acoustic isolator stage, and analog electronics was chosen as a reasonable compromise between form factor, acoustic protection, and electromagnetic interference control. The resulting package lateral dimensions are slightly larger than the detector cross section, while the long dimension of the package is determined by the required hybrid circuit substrate area. An acoustic isolation stage consisting of a plastic foam detector structure added very little to the package dimensions. Enclosure of the detector, a charge amplifier, and a pulse shaping stage in the metal hybrid package provides electrostatic shielding for these EMI sensitive components of the system and produces a package with a high level, low impedance output signal.
Additional acoustic isolation is provided in the Aeronutronic application of these packages by mounting the hybrid package in a central mass of Mallory 2000 (a tungsten-like material), which is then wrapped in a silicone rubber foam. This assembly is itself enclosed in a Mallory 2000 box which is then wrapped in a second layer of foam and installed in the test specimen.

Aeronutronic employs a remotely located electronics package which supplies circuit power voltages and detector bias voltages to each of the three hybrid gamma ray detectors mounted in a common central mass. Each detector package outputs a single ended, high level, low impedance signal consisting of a pulse shaped detector response to a gamma ray encounter. These pulses are threshold detected and counted and formatted for digital transmission and processing by the remote electronics package.

The remainder of this paper is devoted to description of the hybrid gamma ray detector package and its performance viewed as a separate component.

2. Hybrid physical configuration. - The gamma ray detector package (see photograph Fig. 1) is a rectangular hermetically sealed, gold plated Kovar box $14 \mathrm{~mm}$ wide, by $5 \mathrm{~mm}$ high by $30 \mathrm{~mm}$ long. Box walls are $0.5 \mathrm{~mm}$ thick while the lid and floor are $0.25 \mathrm{~mm}$ thick. Package weight is about $8 \mathrm{~g}$.

The detector is located at one end of the package, in a compartment separated from the circuitry by an alumina partition. Eight leads extend from the opposite end of the box. The charge amplifier and pulse shaper stages are built on an alumina substrate using conventional thick film hybrid manufacturing methods. This substrate is bonded to the box floor between the detector compartment and the electrical lead box penetrations. The box lid is electron beam 


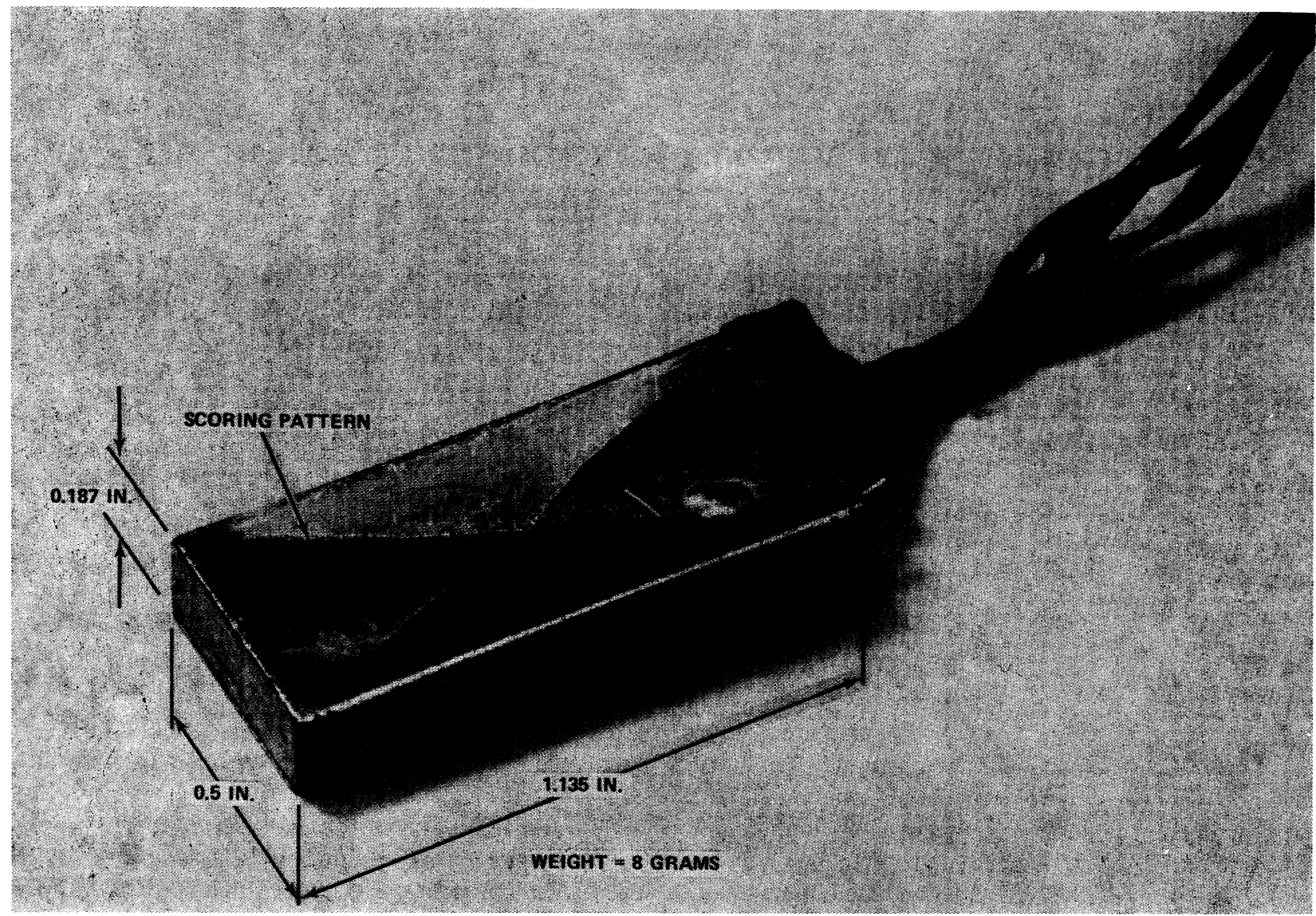

FIG. 1. - Hybrid gamma ray detector package.

welded in place and the lid is subsequently reinforced to reduce the mechanical vibration response of the device.

3. Detector configuration and mounting. - The actual gamma ray detector is a $7 \mathrm{~mm}$ diameter, $2 \mathrm{~mm}$ thick disc of chlorine doped Cadmium Telluride $\left({ }^{1}\right)$, which has a $1 \mathrm{~mm}$ chord cut from the disc. This detector is mounted in the hybrid box with the chord surface parallel to and adjacent to the end of the box. In the Aeronutronic application, gamma photons are incident on the detector through this end of the box and most of them enter the detector through the flat chord cut surface. Detector electrodes consist of chemically deposited platinum discs about $6 \mathrm{~mm}$ diameter located on both large faces of the detector.

Electrical contact is accomplished by epoxying gold lead wires to the center top and bottom of the crystal. With lead wires in place, supporting polyurethane pads are epoxied to the top and bottom crystal face and subsequently to the substrate and lid of the containing box. Figure 2 indicates the manufacturing sequence and the total stack up.

The detector thus packaged has been tested to $100 \mathrm{~g}$

(1) Supplied by Radiation Monitoring Devices, Newton, Mass.

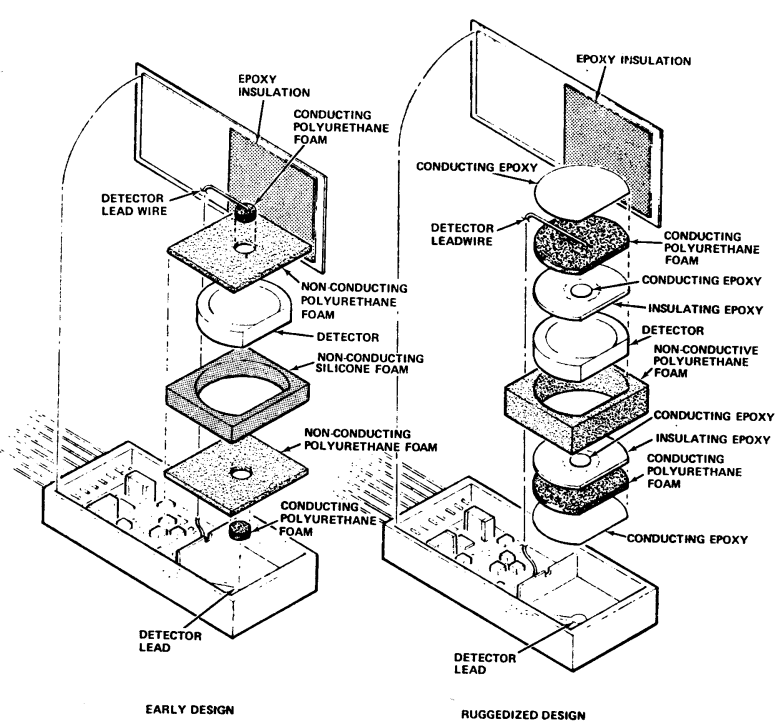

FIG. 2.

sinusoidal input at the critical external isolator frequency $(350 \mathrm{~Hz})$. The detector preamplifier package is then put into an isolator assembly which has been tested to $60 \mathrm{~g}$ in a broad spectrum from 300 to $2000 \mathrm{~Hz}$ and narrow flat ranges of $300-500 \mathrm{~Hz}, 900$ to $1100 \mathrm{~Hz}$ and 1500 to $1700 \mathrm{~Hz}$. No noise spikes penetrate the $80 \mathrm{MV}$ threshold in any of these tests. 
4. Electronic configuration. - The electronic circuit consists of a detector bias circuit, a charge amplifier with test input, and a bandpass filter which serves as a pulse shaper.

The circuit schematic is shown in figure 3 .

The charge amplifier consists of a source follower buffer stage, a bipolar transistor gain stage using a FET constant current active load, and a source follower output stage. A test input to the charge amplifier is provided through a 1 pf capacitor for calibration purposes. This test input is provided with a $47 \mathrm{ohm}$ resistive load to ground, both for convenience in test set-ups and as a noise suppression measure when the test input is not in use. The charge amplifier output is available as a test point, and is also internally connected to the pulse shaper circuit input.

The detector bias circuit consists of a $16 \mathrm{M} \Omega$ load resistor connected between the bias input pin and one detector electrode. A $0.001 \mu \mathrm{f}$ decoupling capacitor is provided for use in combination with the bias supply source impedance to reduce package response to bias voltage ripple or noise. The detector-bias resistor node is connected to the charge amplifie by a larger $(0.001 \mu \mathrm{f})$ capacitor which decouples bias voltage from the charge amplifier. This arrangement allows use of either positive or negative bias voltages, which produces either negative or positive going gamma pulses, as the experimenter choose. In practice some detectors will not function properly with bias voltage reversed although the devices are theoretically bilateral.

The pulse shaper stage is a conventional active bandpass filter employing an operational amplifier gain stage.

Plus and minus $10 \mathrm{~V}$ power is supplied to both charge amplifier and pulse shaper circuits through internal decoupling networks.

The charge amplifier transfer function in $\mathrm{V} / \mathrm{C}$ uses the Laplace transform variable identified by $S$, its expression is gisen by

$$
\frac{V_{\text {out }}}{q}=\frac{-2.5 \times 10^{12} \mathrm{~V} / \mathrm{C}}{1+\frac{2.5 \times 10^{4}}{S}+\frac{0.208 \times 10^{6}}{S^{2}}} .
$$

This is essentially $-2.5 \mathrm{~V} / \mathrm{pC}$ (above $16 \mathrm{kHz}$ ) as far as the gamma response of the detector package is concerned.

The theoretical transfer function of the pulse shaper is :

$$
\begin{aligned}
\frac{V_{\text {out }} \sim}{V_{\text {in }}} & \frac{-\left(S \times 2.1 \times 10^{-3}\right)\left(1+S \times 4.86 \times 10^{-5}\right)}{1+S \times 10^{-3}+S^{2} \times 1.24 \times 10^{-9}} \\
& +S^{3} \times 3.04 \times 10^{-16}
\end{aligned}
$$

This is a gain of about 75 at $290 \mathrm{kHz}$, the mid band frequency for the stage.

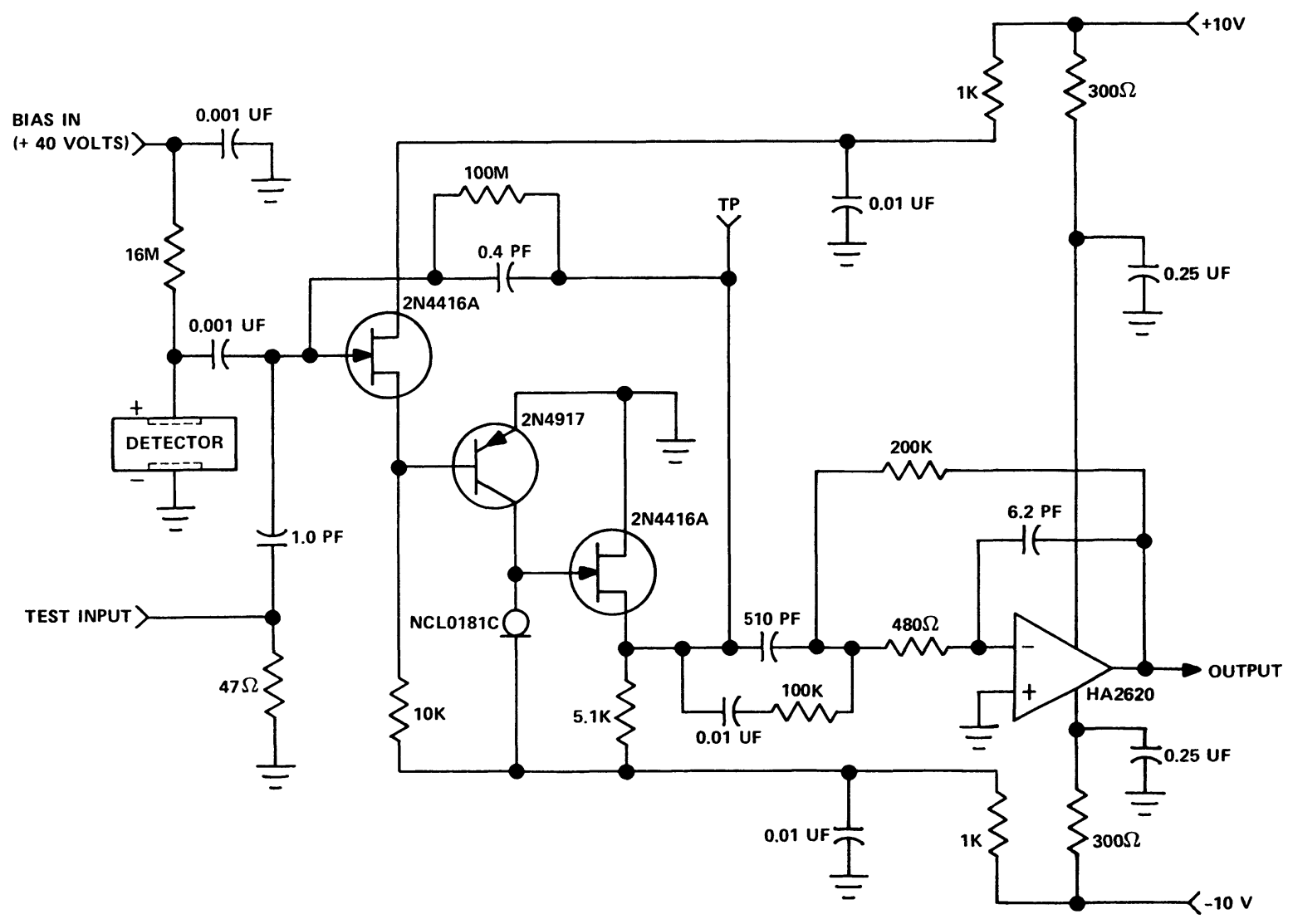

Fig. 3. - Hybrid gamma ray detector package schematic. 
5. Detector Package performance. - The circuit produces a unipolar (negative going for positive bias) full-width, half $\max \sim 1.5 \mu$ s pulse in response to a gamma photon or to a square step at the charge amplifier test point input. A scope photo of a test step response pulse, simulating a gamma response is shown in figure 4. Measured charge step response falls in the range 75 to $125 \mathrm{~V} / \mathrm{pC}$ measured at the pulse peak seen at the shaper stage output.

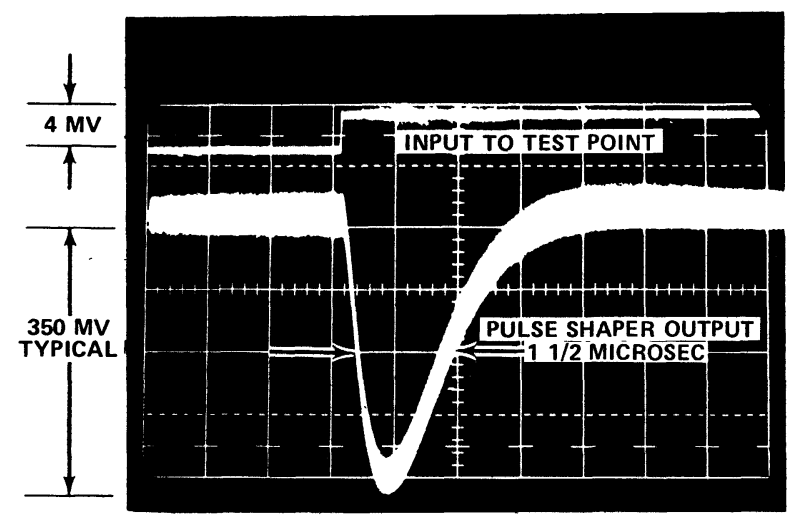

FIG. 4. - Scope photograph of test pulse responses of hybrid package.

Detector package output noise, measured with a true RMS voltmeter is about 6 or $7 \mathrm{mV}$ with detector bias off, and increases to values in the order of $10 \mathrm{mV}$ RMS to $15 \mathrm{mV}$ RMS with $40 \mathrm{~V}$ bias applied. (Appreciably larger noises are a symptom of an inferior detector and are grounds for package rejection).

A theoretical detector photon energy conversion scale function can be estimated using the assumption that the Cadmium Telluride band gap is 1.6 electron volts, which should produce $6.25 \times 10^{-5} \mathrm{pC}$ of negative charge per $\mathrm{keV}$ of photon energy. (Detector bias voltages are so low that positive charges which move slowly in the detector are not collected.) This assumption coupled with the charge gain measured from the test point input yields a package scale factor of about $6 \mathrm{mV} / \mathrm{keV}$. The actual gain measured by observing photo peak pulse amplitudes for Americium (60 keV) photons incident on the detector through the package lid varies between 1.8 and $2.4 \mathrm{mV} / \mathrm{keV}$. The pachage noise equivalent is 4 to $8 \mathrm{keV}$ RMS computed using the measured scale factor. The ratio of charge gain to actual package energy scale factor implies that about $30 \%$ to $40 \%$ of the negative charge released during a gamma ray/detector encounter is actually collected.

All these values assume room temperature $\left(\sim 70{ }^{\circ} \mathrm{F}\right)$ and $40 \mathrm{~V}$ detector bias. Noise is especially sensitive to operating temperature and typically doubles or triples if package temperature is raised to $150{ }^{\circ} \mathrm{F}$.

Counting rate has been measured as a function of temperature, for a number of different photon energies on a prototype device using the older style detector mounting. Typical counting rate vs temperature data measured on two different dates are shown in figure 5. The temperature variation observed is typically less than $2 \%$ over a $50{ }^{\circ} \mathrm{F}$ operating temperature range. The variation in counting performance during the 2 weeks between measurements (except for the

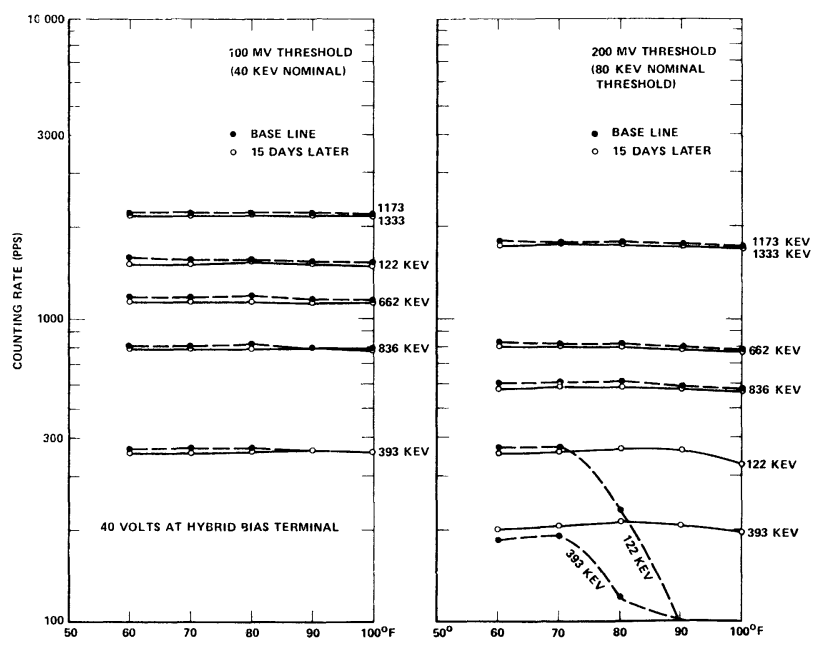

FIG. 5. - Counting rate versus temperature earlier detector suspension design.

low energy photon case discussed below) was generally less than $2 \%$. The limit of accuracy of the experiment was about $1 \%$.

Figure 6 shows counting rate converted to efficiency (ratio of detected counts $\div$ number of incident pho-

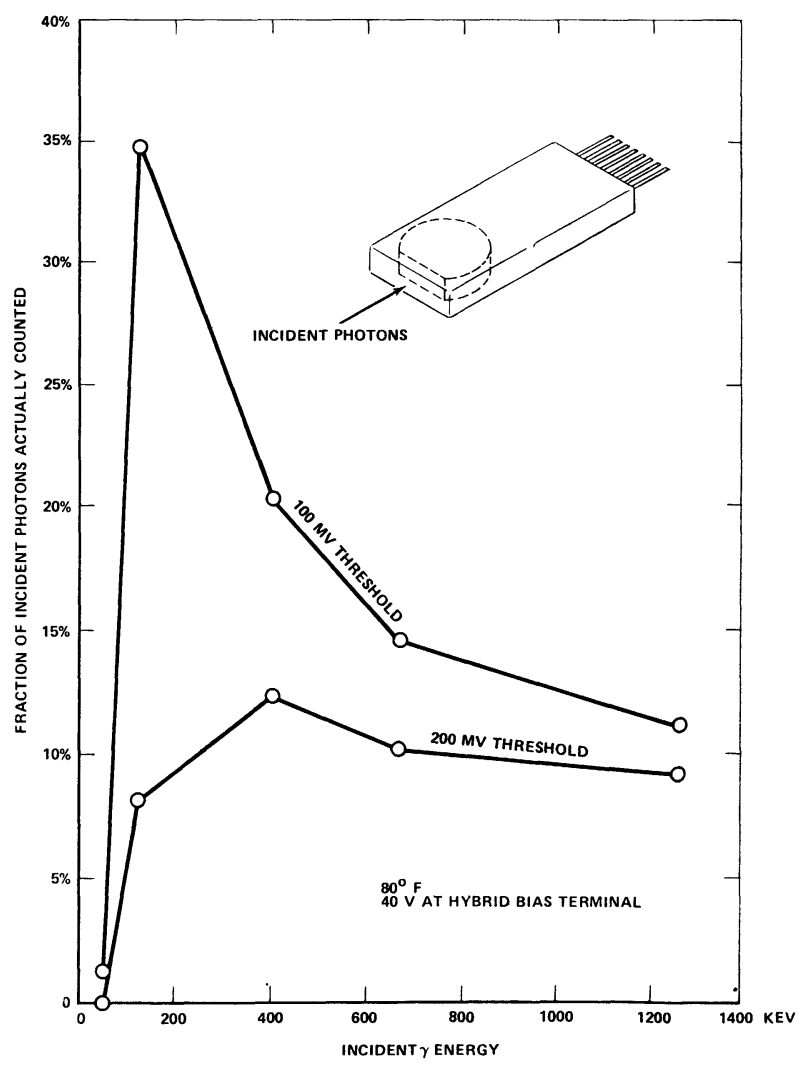

FIG. 6. - Counting efficiency, earlier detector suspension design. 
tons) for the prototype detector package for threshold voltages corresponding to nominal 40 and $80 \mathrm{keV}$ photon energies. Photons are incident on the end of the detector package. Variations in efficiency measured over a two-month period were generally less than $2 \%$ of value except for the low energy photon case.

An exception to the small temperature variation and calibration drift is seen for $122 \mathrm{keV}$ and $343 \mathrm{keV}$ gammas in the figure 5 high threshold data. This variation is probably a consequence of the threshold selection (nominal $80 \mathrm{keV}$ ) lying near the upper limit of the pulse height distribution response for these photons. In such a case, the system efficiency would be very low as shown in figure 6 , and small changes in charge collection efficiency would cause a large percentage variation in count rate.

The unmodified accelerometer response of the package produces an intolerable dynamic base line shift due to vibration in the Aeronutronic application. This response has been successfully suppressed for all practical purposes by adding a single pole high pass filter with corner frequency at $190 \mathrm{kHz}$ between the pulse shaper output and the remote thresholding circuit. This changes the threshold detector input pulse to a bipolar form. The signal to noise ratio measured at the output of this filter is unchanged, but there is about a factor of 2 reduction in voltage response at the filter output.
6. Notes for other applications of this technology. -

1) The noise level of the crystal/preamplifier assembly is approximately $7 \mathrm{mV}(18 \mathrm{keV})$ in the temperature range of 0 to $50^{\circ} \mathrm{C}$ and is fixed at that level by circuitry design.

2) The bias current in the range of 40 to $80 \mathrm{~V}$ is $0-1 \mu \mathrm{A}$. Positive supply voltage is $10 \pm 0.5 \mathrm{~V}$, current drain is $5.0 \mathrm{~mA}$. Negative supply voltage is -- $10 \pm 0.5$ $\mathrm{V}$, current drain $6.0 \mathrm{~mA}$.

3) Stability tests conducted over the temperature range of $0-50^{\circ} \mathrm{C}$ at constant bias and supply voltages for six months indicated an unmeasurable change, $<0.1 \%$ change in counts at a constant input around $600 \mathrm{keV}$.

4) The maximum bias voltage that the package can take is limited by two things :

a) The rating of the components which can be easily upgraded at a penalty of space and size.

b) The dielectric capability of the glass-to-metal seals around the pins.

Either of these limitations can be overcome by repackaging or mounting the crystal external to the box.

5) The device is hermetically sealed so that it could be gas sterilized between patients. Exposure to temperatures above $65^{\circ} \mathrm{C}$ and possible irreversible effects have not been evaluated. 